\title{
Accessory Head of the Flexor Pollicis Longus Muscle (Gantzer Muscle) in a Human Fetus: Case Report and Literature Review
}

\author{
José Aderval Aragão, Lucimario de Carvalho Barros, ${ }^{2}$ Isaias Felipe dos Santos, ${ }^{2}$ lapunira Catarina Sant'Anna \\ Aragão, ${ }^{3}$ Felipe Matheus Sant'Anna Aragão, ${ }^{3}$ Wallace Brener Santana Campos, ${ }^{2}$ Myrla Lorenna Andrade Cruz, ${ }^{2}$ Asaf \\ Ramos dos Santos, ${ }^{2}$ Francisco Prado Reis ${ }^{4}$
}

\begin{abstract}
'Associate Professor of Clinical Anatomy, Department of Morphology, Federal University of Sergipe (UFS), Aracaju, SE, Brazil
${ }^{2}$ Medical student at the Federal University of Sergipe (UFS), Aracaju, SE, Brazil

${ }^{3}$ Medical Student, University Center of Volta Redonda (UNIFOA), Volta Redonda, RJ, Brazil

${ }^{4}$ Titular Professor, Medical School of Tiradentes University (UNIT), Aracaju, SE, Brazil
\end{abstract}

Disclose and conflicts of interest: none to be declared by all authors

\section{ABSTRACT}

Introduction: the accessory head of the flexor pollicis longus muscle (Gantzer muscle) is an additional muscle of the anterior compartment of the forearm that has a very variable incidence in the population.

Case report: During a routine dissection, we found a fusiform muscle mass with tenuous tendons in the deep anterior portion of the right forearm of a fetus.

Conclusion: Due to its location and relationship with the surrounding nervous structures, the presence of the Gantzer muscle may be related to the triggering of clinical syndromes, such as the anterior interosseous nerve and pronator syndrome.

Keywords: Gantzer muscle, forearm, variation, dissection

\section{Introduction}

Several cases of anatomical variations of the forearm musculature are described in the literature. In 1813, Gantzer described an accessory muscle of the forearm that joins the flexor pollicis longus as an anatomical variant that bears his name, and it has been widely debated..$^{1-7}$ The Gantzer muscle is an additional muscle of the deep anterior compartment that can be found bilaterally or unilaterally, which has the function of assisting in the flexion of the forearm. ${ }^{8}$ Its origin, despite being quite variable, can occur in the following places: deep surface of the superficial flexor muscle of the fingers, coronoid process of the ulna, medial epicondyle and/or as an aggregation of two or all of the anteriors. ${ }^{1,3-9}$ Its insertion, on the other hand, occurs more frequently on the medial margin of the tendon part of the flexor digitorum longus muscle., ${ }^{2,5,8,10-12}$ Regarding its topography with neurovascular structures, the accessory head of the flexor pollicis longus can be found anteriorly, ${ }^{9,11,13,14}$ as well as posteriorly to the anterior interosseous nerve, ${ }^{10,14}$ and rarely by the median nerve. ${ }^{2-4,7,9}$

Its vascularization has been scarcely described, but for Jones et al., ${ }^{2}$ this irrigation originates from several vessels: direct branch of the ulnar artery (55.9\%), anterior recurrent ulnar artery (17.6\%), anterior interosseous artery (11.8\%), and median artery (2.8\%). Also in relation to its morphology, the accessory head of the flexor pollicis longus muscle can be classified into several types: thin (similar to a strip), fusiform, triangular, papillary, girdle and bulky. ${ }^{2-4}$ However, its morphometry is quite variable, in adults the muscle length is on average $78.86 \pm 10.94 \mathrm{~mm}$, its tendon 8.53 \pm 9.02 , the muscle belly $72.71 \pm 12.43$ and its width 4.15 $\pm 1.71 .^{2-4,6}$

Anterior interosseous nerve syndrome is believed to be caused by trauma and structural abnormalities in the forearm, ${ }^{8}$ but the presence of the accessory head of the flexor pollicis longus muscle (the Gantzer muscle) can lead to compression of the anterior interosseous nerve leading to paralysis, also called Kiloh-Nevin Syndrome, and should be suspected in patients with carpal tunnel syndrome who do not respond to conservative or surgical therapy, ${ }^{8,15}$ as well as in surgical procedures from decompressive fasciotomies for compartment syndrome of the forearm. ${ }^{8}$ Therefore, our objective was to report and describe the existence of the accessory head of the flexor pollicis longus muscle in a male fetus.

\section{Case Report}

During a routine dissection of a 33-week-old human fetus cadaver, male, in the human anatomy laboratory of the Department of Morphology of the Federal University of Sergipe, a muscle was found on the anterior surface of the right forearm that was found deep in the flexor carpi radialis, pronator teres and flexor digitorum superficialis muscles. Its muscular belly was found medial and deep to the median nerve, where it received innervation from 
the anterior interosseous nerve, together with the branches to the long flexor muscle of the fingers; its irrigation was performed by a branch of the anterior interosseous artery. This muscle originated in the medial epicondyle, through a $12.80 \mathrm{~mm}$ long tendon, which continued with a fusiform muscle belly 20.35 $\mathrm{mm}$ long and $1.78 \mathrm{~mm}$ wide, which in turn it was inserted through another long tendon measuring 18.41 $\mathrm{mm}$, in the ulnar portion of the flexor pollicis longus muscle in its distal third (Figure 1). for males and 39\% for females. Regarding laterality, Dykes, Anson ${ }^{19}$ showed the following prevalences: $28 \%$ on the right side, $25 \%$ on the left side and $18 \%$ bilateral. However, these data are in conflict with the results found by Jones et al., ${ }^{2}$ who found it more frequently bilaterally (58.4\%) than unilaterally (25\% to the right and $8.4 \%$ to the left), which it is also in agreement with several other authors, ${ }^{13,14,20}$ but in our study we only found the muscle on the right side. This high incidence of the Gantzer muscle may be advantageous in

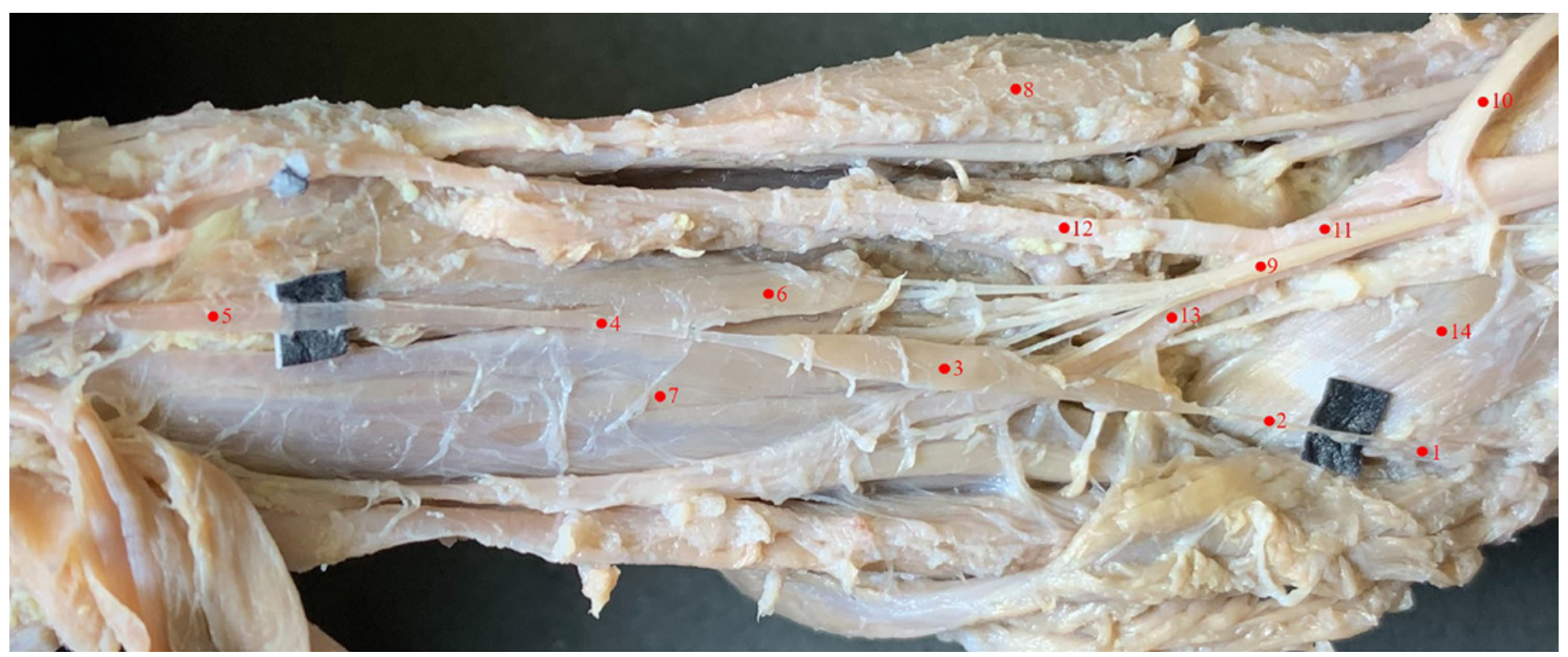

Figure 1. Accessory head of the flexor pollicis longus muscle (Gantzer muscle).

1. Medial epicondyle

2. Proximal tendon of the accessory head of the flexor pollicis longus muscle

3. Muscular belly of the accessory head of the flexor pollicis longus muscle

4. Distal tendon of the accessory head of the flexor pollicis longus muscle

5. Tendon formed by the flexor pollicis longus muscle and its accessory head

6. Flexor pollicis longus muscle

7. Flexor digitorum profundus muscle

8. Brachioradialis muscle

9. Anterior interosseous nerve with its branches

10. Median nerve folded

11. Brachial artery

12. Radial artery

13. Ulnar artery

14. Brachial muscle

\section{Discussion}

The existence of the accessory head of the flexor pollicis longus muscle (Gantzer muscle) in a part of the population can be explained by the way in which the flexor muscles of the forearm develop. In embryological development, initially there is the appearance of a common flexor mass in the embryo, which then differentiates into superficial and deep layers. The deep layer, which has a slower development compared to the superficial layer, is responsible for creating the flexor pollicis longus, flexor digitorum deep and pronator quadratus muscles. However, when an incomplete differentiation of this layer occurs, the accessory head of the flexor pollicis longus muscle is originated. ${ }^{2,16}$

The prevalence of the accessory head of the flexor pollicis longus muscle is debatable. According to Bergman et al., ${ }^{17}$ this incidence rate ranges from a minimum of $33.3 \%$ in European Caucasians to a maximum of $89.3 \%$ in blacks, with Asians in the middle of this range. Although the prevalence according to sex is not clear, for Wood $^{18}$ this rate varies from $36 \%$

performing procedures to restore function in case of severe traumatic muscle loss in crush and compression injuries, multiple nerve palsy as in Hansen's disease and after complete resection in infectious and neoplastic conditions in the forearm and hand.

Regarding the morphology of the accessory head of the flexor pollicis longus muscle, in our study it had a fusiform aspect, which is consistent with the findings found by other authors. ${ }^{2,8,14,15}$ In addition to this fusiform shape, the muscle can be of the slender type (in ribbon), papillary, triangular, girdle, and voluminous, ${ }^{2-4}$ being the fusiform shape the most frequent in $83.69 \%$ of cases. ${ }^{8}$ Regarding morphometry, we found a proximal tendon measuring $12.80 \mathrm{~mm}$ in length and a distal one measuring $18.41 \mathrm{~mm}$, with a muscle belly of $20.35 \mathrm{~mm}$. Our parameters are different from those described in the literature, as they were performed in a 33-monthold human fetus, and not in adults, as reported by several authors, where in most cases the accessory head of the flexor pollicis longus muscle had a single tendon and muscle belly, being its length and width 
grouped of $8.53 \pm 9.02$ and $72.71 \pm 12.43$, respectively. ${ }^{2-4,8}$

In our study, the origin of the accessory head of the flexor pollicis longus muscle (Gantzer muscle) was found in the medial epicondyle of the humerus, while its insertion occurred in the ulnar edge of the flexor pollicis longus muscle, which is consistent with the reports from various authors. . $^{6,8,10,13,21,22}$

The pooled prevalence of accessory head innervation of the flexor pollicis longus occurs mainly through the anterior interosseous nerve in $97.3 \%$ of cases, ${ }^{2,6,8,812,13,21,22}$ which is in agreement with our report, where its innervation was performed by the anterior interosseous nerve, which later passed the accessory head. This location is of great clinical importance, as it could trigger the anterior interosseous nerve syndrome. Its vascularization has been little reported in the literature, ${ }^{2,23}$ and in our study, the accessory head of the flexor pollicis longus muscle was irrigated by a branch of the anterior interosseous artery.

\section{Conclusion}

Knowledge of the accessory head of the flexor pollicis longus muscle (Gantzer muscle) is undoubtedly vital not only for medical students but for clinicians in relation to the diagnosis and treatment of nerve syndromes such as Kiloh-Nevin and pronator syndrome, as well as for orthopedic surgeons performing decompressive fasciotomies and in accesses to address the proximal head of the radius or elbow joint.

\section{References}

1. Macalister A. Additional observatins on muscular anomalies in human anatomy (third series), with a catalogue of the principal musclular variations hitherto published. Transactions of the Royal Irish Academy Science. 1875;25:1-134.

2. Jones M, Abrahams PH, Sañudo JR, Campillo M. Incidence and morphology of accessory heads of flexor pollicis longus and flexor digitorum profundus (Gantzer's muscles). J Anat. 1997 Oct;191 ( Pt 3)(Pt 3):451-5.

3. Kara A, Elvan O, Yildiz S, Ozturk H. Accessory head of flexor pollicis longus muscle in fetuses and adult cadavers and its relation to anterior interosseous nerve. Clin Anat. 2012 Jul;25(5):601-8.

4. Tamang BK, Sinha P, Sarda RK, Shilal P, Murlimanju BV. Incidence and morphology of accessory head of flexor pollicis longus muscle - an anatomical study. Journal of Evolution of Medical and Dental Sciences. 2013 Sep;2(36):6800-6806.

5. Shantakumar RS, Sirasanagandla SR, Nayak SB, Gadahad MRK, Somayaji SN, Kumar N. Multiple tendons of the additional belly of flexor pollicis longus in the carpal tunnel: Embryological perspective and their clinical significance. Forensic Medicine and Anatomy Research. 2013 Oct:1(4):70-73.

6. Roy J, Henry BM, Pękala PA, Vikse J, Ramakrishnan PK, Walocha JA, Tomaszewski KA. The prevalence and anatomical characteristics of the accessory head of the flexor pollicis longus muscle: a metaanalysis. PeerJ. 2015 Oct 1;3:e1255.

7. Caetano EB, Sabongi JJ, Vieira LÂ, Caetano MF, Moraes DV. Gantzer muscle. An anatomical study. Acta Ortop Bras. 2015 MarApr;23(2):72-5.

8. Gunnal SA, Siddiqui AU, Daimi SR, Farooqui MS, Wabale RN. A Study on the Accessory Head of the Flexor Pollicis Longus Muscle (Gantzer's Muscle). J Clin Diagn Res. 2013 Mar;7(3):418-21.

9. Mangini U. Flexor pollicis lungus muscle. Its morphology and clinical significance. J Bone Joint Surg Am. 1960 Apr;42-A:467-70.

10. al-Qattan MM. Gantzer's muscle. An anatomical study of the accessory head of the flexor pollicis longus muscle. J Hand Surg Br. 1996 Apr;21(2):269-70.

11. Shirali S, Hanson M, Branovacki G, Gonzalez M. The flexor pollicis longus and its relation to the anterior and posterior interosseous nerves. J Hand Surg Br. 1998 Apr;23(2):170-2.

12. Pai MM, Nayak SR, Krishnamurthy A, Vadgaonkar R, Prabhu LV, Ranade AV, Janardhan JP, Rai R. The accessory heads of flexor pollicis longus and flexor digitorum profundus: Incidence and morphology. Clin Anat. 2008 Apr;21(3):252- 8.

13. Oh CS, Chung IH, Koh KS. Anatomical study of the accessory head of the flexor pollicis longus and the anterior interosseous nerve in Asians. Clin Anat. 2000;13(6):434-8.

14. Mahakkanukrauh $P$, Surin $P$, Ongkana $N$, Sethadavit $M$, Vaidhayakarn P. Prevalence of accessory head of flexor pollicis longus muscle and its relation to anterior interosseous nerve in Thai population. Clin Anat. 2004 Nov;17(8):631-5.

15. El Domiaty MA, Zoair MM, Sheta AA. The prevalence of accessory heads of the flexor pollicis longus and the flexor digitorum profundus muscles in Egyptians and their relations to median and anterior interosseous nerves. Folia Morphol (Warsz). 2008 Feb;67(1):63-71.

16. Hollinshead WH. Anatomy for surgeons. New York, Harper and Row. 1964; 3:412.

17. Bergman RA, Afifi AK, Miyauchi R. Illustrated Encyclopedia of Human Anatomic Variation: Opus I: Muscular System: Alphabetical Listing of Muscles: F. URL: https://www.anatomyatlases.org/ AnatomicVariants/MuscularSystem/Text/F/22Flexor.shtml. [Internet]. [accessed September 2021].

18. Wood J. Variations in Human Myology Observed during the Winter Session of 1867-68 at King's College, London. Proceedings of the Royal Society of London. 1867 - 1868;16:483-525.

19. Dykes J, Anson BJ. The accessory tendon of the flexor pollicis longus muscle. Anat Rec. 1944 Sep;90(1):83-87.

20. Potu BK, Gorantla VR, Pulakunta T, Rao MS, Mamatha T, Vollala VR, Nayak SR. 2007. Accessory head of flexor pollicis longus muscle and its significance in anterior interosseous nerve syndrome: Case report and review. Int. J. Morphol. 2007;25(4):911-914.

21. Yang K, Jung SJ, Lee H, Choi IJ, Lee JH. Topographical relations between the Gantzer's muscle and neurovascular structures. Surg Radiol Anat. 2017 Aug;39(8):843-848.

22. Ballesteros DR, Forero PL, Ballesteros LE. Accessory head of the flexor pollicis longus muscle: anatomical study and clinical significance. Folia Morphol (Warsz). 2019;78(2):394-400. doi: 10.5603/FM.a2018.0091.

23. Vollala VR, Nagabhooshana S, Bhat SM, Potu BK, Rodrigues V, Pamidi N. Multiple arterial, neural and muscular variations in upper limb of a single cadaver. Rom J Morphol Embryol. 2009;50(1):129-35. 


\section{Mini Curriculum and Author's Contribution}

1. José Aderval Aragão - MD; PhD. Contribution: Conception, Design, Supervision, Writing, Critical Review and final approval. ORCID: https://orcid.org/0000-0002-2300-3330

2. Lucimario de Carvalho Barros - Medical Student. Contribution: Data Collection and/or Processing, Analysis and/or Interpretation, Critical Review and final approval. ORCID: https://orcid.org/0000-0003-4544-1363

3. Isaias Felipe dos Santos - Medical Student. Contribution: Data Collection and/or Processing, Analysis and/or Interpretation, Critical Review and final approval. ORCID: https://orcid.org/0000-0002-1717-7449

4. Iapunira Catarina Sant'Anna Aragão - Medical Student. Contribution: Data Collection and/or Processing, Analysis and/or Interpretation, Critical Review and final approval. ORCID: https://orcid.org/0000-0002-5298-537X

5. Felipe Matheus Sant'Anna Aragão - Medical Student. Contribution: Data Collection and/or Processing, Analysis and/ or Interpretation, Critical Review and final approval. ORCID: https://orcid.org/0000-0001-9211-7000

6. Wallace Brener Santana Campos - Medical Student. Contribution: Data Collection and/or Processing, Analysis and/ or Interpretation, Critical Review and final approval. ORCID: https://orcid.org/0000-0003-2355-4690

7. Myrla Lorenna Andrade Cruz - Medical Student. Contribution: Fundings, Materials, Data Collection and/or Processing, Literature Review and final approval. ORCID: https://orcid.org/0000-0002-7557-5859

8. Asaf Ramos dos Santos - Medical Student. Contribution: Fundings, Materials, Data Collection and/or Processing, Literature Review and final approval. ORCID: https://orcid.org/0000-0002-4618-0241

9. Francisco Prado Reis - MD; PhD. Contribution: Conception, Design, Supervision, Writing, Critical Review and final approval. ORCID: https://orcid.org/0000-0002-7776-1831

Received: July 12, 2021

Accepted: September 17, 2021
Corresponding author

José Aderval Aragão

E-mail: adervalufs@gmail.com 